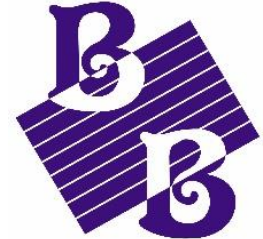

BioBacta
Journal of Bioscience and Applied Research

www.jbaar.org

\title{
Morphological and molecular characterization of some olive (Olea europaea) cultivars in El-Arish, Egypt
}

\author{
Amina Abdel Hamid Mohamed ${ }^{1 *}$, Mohamed A. Nagaty ${ }^{2}$, Manal M. S. El-Baghdady ${ }^{1}$, Khaled H. Radwan 1,3
}

1 Agricultural Genetic Engineering Research Institute, Agricultural Research Center, Giza -12619, Egypt.

2 Plant Production Department, Faculty of Environmental Agricultural Sciences, Arish University, El-Arish, North Sinai, Egypt.

${ }^{3}$ National Biotechnology Network for Expertise- Egypt.

* Corresponding author at Molecular Genetics and Genome Mapping Research Department, Agricultural Genetic Engineering Research Institute, Agricultural Research Center, Giza -12619 Egypt. Tel. 0020235727831, E-mail address: amina.rady@protonmail.com

DOI: 10.21608/jbaar.2017.126470

\begin{abstract}
Morphological characters, along with three different random PCR based markers, (ISSR, SCoT, and RAMP) were used to characterize and to assess the genetic diversity among the main nine olive cultivars in El-Arish, Egypt. Analyses of 16 morphological characters revealed the existence of a recorded genetic variability among the studied cultivars. Moreover, 12 ISSR primers, 13 SCoT primers, and 11 RAMP primer combinations (PCs) produced 197, 242, and 172 of total loc with 163, 236, and 140 of them being polymorphic respectively. Average polymorphism information content (PIC value) of 0.26, 0.31, and 0.26 detected for ISSR, SCoT, and RAMP markers respectively. Based on morphological and the selected molecular markers, the nine olive cultivars were grouped in two distinct clusters. The highest genetic similarity observed was that between Teffahi and Ageezi, while the least similarity was that recorded between Ageezi Shami and Koroneiki.

The tested marker systems would serve as a complementary tool to provide a more complete understanding of the diversity available in olive populations in Egypt.
\end{abstract}

Keywords: olive cultivars, El-Arish, Egypt, Olea europaea, ISSR, SCoT, RAMP

\section{Introduction}

Olive (Olea europaea sub. sp europaea var. europaea) was cultivated for thousands of years because of its rich genetic pool, its remarkable cultural and economic importance, and its drought and salt-tolerant trees. Because of the wide variety of cultivars and accessions, the olive has, a good knowledge of its genetic variation as well as the relationships between olive cultivars is important for the development of better olive cultivations. It is also important to study less common cultivars that are considered an important pool for olive genetic diversity that is affected by the introduction of commercial cultivars to the modern olive orchards. Thus, it is important to correctly identify the olive cultivars under study. 
Different characters were used to measure the genetic variability between olive resources worldwide (Muzzalupo et al., 2014) as well as in Egypt (Hegazi et al., 2012). Traditionally, morphological traits were used to characterize olive trees. However, certain limitations associated with these traits; being affected by environmental factors as well as the need for observations of the mature plants have made them less popular in germplasm identification (Belaj et al., 2011). Molecular markers offered more robust and reliable tools for germplasm characterization and diversity analysis to complement morphological analyses. Different authors used RAPDs (Kaya and YilmazGokdogan, 2015), AFLPs (Grait-Kamoun et al., 2006), SSRs (Richards et al. 2009), and SNPs (Le Cunff et al. 2008). This trend is increasingly being used for this purpose either alone and/ or in combination with phenotypic traits; combined morphological characters with SSR (Sorkheh and Khaleghi, 2016); and with RAPD (Parra-Lobato MC et al., 2012) to better characterize olive germplasm.

Inter-simple sequence repeats (ISSR) marker amplifies repeaters' anchored between SSRs. It is characterized by being highly informative; reproducible as well as being polymorphic. The start codon targeted (SCoT) marker is based on the short-conserved region in plants that flanking the start codon. It is characterized by being highly reproducible; requires no prior sequence information and being correlated to functional genes. Another high polymorphic marker is the Random Amplified Microsatellite Polymorphism (RAMP). RAMP combines two markers; random amplified polymorphic DNA (RAPD) and inter simple sequence repeat (ISSR). It is characterized by being highly polymorphic as well as being widely distributed throughout the genome and above all, it is a low-cost marker.

The present work reports the employment of morphological traits and PCR-based molecular markers (ISSR, SCoT, and RAMP) to characterize genetic diversity and relationships among nine olive cultivars that the most common in Arish, Egypt. Also, a comparison between these approaches was carried out to assess their efficiency in evaluating genetic diversity levels and to efficiently explore cultivar identity and the relationships among the olive cultivars under study.

\section{Materials and Methods}

\section{Plant Materials and Morphological characters}

Thirty replicates from each cultivar were used to test the morphological and molecular variations among the 9 olive cultivars from El-Arish, North Sinai governorate (Table 1). The morphological characteristics were used to distinguish olive cultivars based on those described by the International Olive Council (COI, 1997). Morphological characters were measured manually and recorded for 16 selected characters including leaf characters (5 characters), shoot characters (7characters), and flower (4 characters) (Table 2).

Table (1): List of the nine olive cultivars studied and their corresponding country of origin.

\begin{tabular}{|l|l|l|}
\hline & Cultivar & Origin \\
\hline $\mathbf{1}$ & Chemlali & Tunisia \\
\hline $\mathbf{2}$ & Ageezi Shami & Egypt \\
\hline $\mathbf{3}$ & Manzanillo & Spain \\
\hline $\mathbf{4}$ & Frantoio & Italy \\
\hline $\mathbf{5}$ & Coratina & Italy \\
\hline $\mathbf{6}$ & Koroneiki & Greece \\
\hline $\mathbf{7}$ & Teffahi & Egypt \\
\hline $\mathbf{8}$ & Kalamata & Greece \\
\hline $\mathbf{9}$ & Picual & Spain \\
\hline
\end{tabular}

\section{Genomic DNA extraction}

Young leaves of olive were used to extract genomic DNA using DNeasy plant mini-kit according to manual's directives (Qiagen, Valencia, CA, USA) and the concentration and purity of DNA were calculated using Thermo Scientific NanoDrop 200 spectrophotometer at 260 and $280 \mathrm{~nm}$.

\section{ISSR analysis}


Out of 24 ISSR-PCR primers (Eurofins, Germany) initially tested, twelve of them were further used to screen the nine olive cultivars based on the reproducible and scorable profiles they produced. Primer names and their corresponding sequences are shown in Table (3). The reaction was applied in a final reaction volume of $25 \mu \mathrm{l}$ containing $200 \mu \mathrm{M}$ of dNTPs, $2 \mathrm{mM}$ of $\mathrm{MgCl}_{2}$ in $1 \mathrm{X}$ GoTaq ${ }^{\circledR}$ Flexi buffer, $20 \mathrm{pM}$ of primer, $30 \mathrm{ng}$ of template DNA, and $1 \mathrm{U}$ of GoTaq ${ }^{\circledR}$ Flexi DNA (Promega; Promega Corporation, USA). The amplification process was carried out in a Gene Amp® PCR System 9700 thermal cycler (Applied Biosystems) and the program applied was: $94^{\circ} \mathrm{C} / 5 \mathrm{~min}$ (1 cycle); $\left[94^{\circ} \mathrm{C} / 1 \mathrm{~min}, 47^{\circ} \mathrm{C} / 1 \mathrm{~min}, 72^{\circ} \mathrm{C} / 2 \mathrm{~min}\right](40$ cycles); $72^{\circ} \mathrm{C} / 7 \mathrm{~min}$ ( 1 cycle) and was stored at $4^{\circ} \mathrm{C}$.

\section{SCoT analysis}

Out of 36 primers, thirteen SCoT primers showed the highest polymorphism and were used for further identification of the 9 olive cultivars (Table 4). PCR amplification were performed in $25 \mu \mathrm{l}$ volume in $1 \mathrm{X}$ of GoTaq Flexi buffer, $1.5 \mathrm{mM} \mathrm{MgCl} 2,0.2 \mathrm{mM}$ dNTPs, $0.20 \mathrm{pmol} / \mu \mathrm{l}$ for every primer, $1 \mathrm{U}$ GoTaq Flexi DNA and $50 \mathrm{ng}$ of template DNA. The amplification process was carried out as follows: an initial denaturation step at $94{ }^{\circ} \mathrm{C}$ for $3 \mathrm{~min}$, followed by 35 cycles of $94^{\circ} \mathrm{C}$ for $50 \mathrm{~s}, 50^{\circ} \mathrm{C}$ for $1 \mathrm{~min}$, and $72{ }^{\circ} \mathrm{C}$ for $2 \mathrm{~min}$ and a final elongation of $7 \mathrm{~min}$ at $72^{\circ} \mathrm{C}$.

\section{RAMP analysis}

The RAMP marker is a combination of RAPD and ISSR (Table 5). 30 primer combinations (PCs) were initially examined to assess the consistency of the products. Eleven PCs were further chosen for the analyses. The amplification reaction was performed in a $25 \mu \mathrm{l}$ reaction volume containing $1 \mathrm{X}$ of GoTaq Flexi buffer, $2 \mathrm{mM} \mathrm{MgCl}_{2}, 0.2 \mathrm{mM}$ dNTPs, $20 \mathrm{pmol}$ from each primer, $1.5 \mathrm{U}$ GoTaq Flexi DNA, and $30 \mathrm{ng}$ template DNA. PCR amplification was programmed for 40 cycles after an initial denaturation cycle of $5 \mathrm{~min}$ at $94^{\circ} \mathrm{C}$. Each cycle consisted of $1 \mathrm{~min}$ for denaturation at $94^{\circ} \mathrm{C}, 1 \mathrm{~min}$ for annealing at $38^{\circ} \mathrm{C}$, and $2 \mathrm{~min}$ for an extension at $72^{\circ} \mathrm{C}$, followed by a final cycle of extension for $7 \mathrm{~min}$ at $72^{\circ} \mathrm{C}$.

PCR products for ISSR, ScoT, and RAMP were separated and photographed using Imager Gel Doc $\mathrm{XR}^{+}$ System provided with Image Lab Software, BioRad. The amplified products were compared against the 1 $\mathrm{Kb}$ DNA molecular weight standard (Thermo Gene Ruler).

\section{Data analysis}

Morphological characteristics were analyzed using Euclidean distances and the genetic similarity for molecular data was calculated using the pairwise comparisons according to the Dice coefficient (Dice, 1945). SPSS software was used to calculate both methods and to construct dendrograms based on similarity estimates using the unweighted pair-group method with arithmetic average (UPGMA) (Sokal and Michener, 1958). Mantel test (Mantel, 1967) was carried out using the Power Marker program.

Molecular markers (ISSR, SCoT, and RAMP) results were scored as a binary data matrix (existence (1) or absent (0). The performances of these markers were determined by using; an observed number of alleles $(\mathrm{Na})$, effective number of alleles $(\mathrm{Ne})$ (Hartl and Clark,1989), Nei's gene diversity (H), and Shannon's information index of Diversity (Shannon, 1949) were estimated using POPGENE software V1.32 (Yeh et al., 1997). The Polymorphic Information Content (PIC) was estimated using the Power Marker program version (3.25) according to Botstein et al. (1980). The multiplex ratio (MR) effective multiplex ratio (EMR) and the marker index (MI) were calculated according to Powell et al. (1996).

\section{RESULTS AND DISCUSSION}

Qualitative morphological characters; along with molecular markers represent a reliable method to characterize genetic diversity within species. PCRbased random markers, i.e. ISSRs, SCoT, and RAMP 
were utilized to assess the genetic diversity among the main nine olive cultivars grown in El-Arish.

\section{Morphological Characterization:}

Olive genotypes selected were evaluated using 16 qualitative morphological characters. These characters included leaf, growth, and inflorescence traits that exhibited considerable morphological variability (Table 2). The most discriminative traits are leaf length, leaf width, leaf area, shoot length, feather shoot length, and feather internode that showed the highest values of diversity, giving a proportion of distinguishable pairs higher than other traits. Also, inflorescence characters, such as the number of flowers, inflorescence length/width, inflorescence width, and several flowers showed considerable variability. Nevertheless, Hannachi et al., 2008; Zaher H.et al. 2011 and Dastkar et al.2013 used leaf characters (length, width, and length/width ratio) and fruit characters as a common morphological trait to discriminate olive cultivars. The high significance recorded between quantitative morphological traits could be attributed to the consistency of data and low environmental influence (Belaj et al., 2011).

Table 2: Morphological characters data, their corresponding abbreviations of the nine studied olive cultivars.

\begin{tabular}{|c|c|c|c|c|c|c|c|c|c|c|}
\hline Treat & Cultivar & Chemlali & $\begin{array}{l}\text { Ageezi } \\
\text { Shami }\end{array}$ & Manzanillo & Frantoio & Coratina & Koroneiki & Teffahi & Kalamata & Picual \\
\hline Leaf length & LL & $5.57^{\mathrm{bc}}$ & $3.95^{\mathrm{d}}$ & $3.90^{\mathrm{d}}$ & $4.27^{\mathrm{d}}$ & $4.42^{\mathrm{d}}$ & $5.95^{\mathrm{b}}$ & $5.17^{\mathrm{c}}$ & $7.37^{\mathrm{a}}$ & $5.22^{\mathrm{c}}$ \\
\hline Leaf width & LW & $0.85^{\mathrm{e}}$ & $1.00^{\text {cde }}$ & $1.15^{\mathrm{bcd}}$ & $0.95^{\mathrm{de}}$ & $1.17^{\mathrm{bcd}}$ & $1.25^{\mathrm{b}}$ & $1.22^{\mathrm{bc}}$ & $1.52^{\mathrm{a}}$ & $1.12^{\mathrm{bcd}}$ \\
\hline leaf area & LA & $1.19^{\mathrm{de}}$ & $0.99^{\mathrm{c}}$ & $1.13^{\mathrm{de}}$ & $1.01^{\mathrm{e}}$ & $1.29^{\mathrm{cde}}$ & $1.85^{\mathrm{b}}$ & $1.58^{\mathrm{bc}}$ & $2.81^{\mathrm{a}}$ & $1.48^{\mathrm{cd}}$ \\
\hline Leaf Fresh weight & LFW & $0.179^{\mathrm{a}}$ & $0.074^{\mathrm{c}}$ & $0.109^{\mathrm{bc}}$ & $0.082^{\mathrm{bc}}$ & $0.089^{\mathrm{bc}}$ & $0.213^{\mathrm{a}}$ & $0.125^{\mathrm{b}}$ & $0.224^{\mathrm{a}}$ & $0.117^{\mathrm{bc}}$ \\
\hline Leaf Dry weight & LDW & $0.110^{\mathrm{a}}$ & $0.052^{\mathrm{bc}}$ & $0.06^{\mathrm{bc}}$ & $0.035^{\mathrm{c}}$ & $0.052^{\mathrm{bc}}$ & $0.136^{\mathrm{a}}$ & $0.064^{\mathrm{bc}}$ & $0.125^{\mathrm{a}}$ & $0.071^{\mathrm{b}}$ \\
\hline Shoot length & SL & $21.25^{\mathrm{bc}}$ & $17.75^{\text {bcd }}$ & $14.00^{\text {cd }}$ & $12.00^{\mathrm{d}}$ & $39.62^{\mathrm{a}}$ & $23.00^{\mathrm{b}}$ & $16.87^{\text {bcd }}$ & $15.25^{\text {bcd }}$ & $16.50^{\text {bcd }}$ \\
\hline Node number & NN & $10.00^{\mathrm{a}}$ & $13.00^{\mathrm{a}}$ & $10.25^{\mathrm{a}}$ & $10.75^{\mathrm{a}}$ & $15.75^{\mathrm{a}}$ & $12.50^{\mathrm{a}}$ & $11.25^{\mathrm{a}}$ & $11.50^{\mathrm{a}}$ & $12.75^{\mathrm{a}}$ \\
\hline Internode length & NFS & $2.10^{\mathrm{ab}}$ & $1.22^{\mathrm{c}}$ & $1.57^{\mathrm{bc}}$ & $1.12^{\mathrm{c}}$ & $2.67^{\mathrm{a}}$ & $2.17^{\mathrm{ab}}$ & $1.65^{\mathrm{bc}}$ & $1.20^{\mathrm{c}}$ & $1.70^{\mathrm{bc}}$ \\
\hline No. Feather shoot & FSL & $2.00^{\mathrm{b}}$ & $2.00^{\mathrm{b}}$ & $1.25^{\mathrm{b}}$ & $1.25^{\mathrm{b}}$ & $5.50^{\mathrm{a}}$ & $1.50^{\mathrm{b}}$ & $2.25^{\mathrm{b}}$ & $1.00^{\mathrm{b}}$ & $1.50^{\mathrm{b}}$ \\
\hline Feather shoot length & NFN & $5.1^{\mathrm{abc}}$ & $6.1^{\mathrm{ab}}$ & $2.7^{\mathrm{c}}$ & $4.3^{\mathrm{bc}}$ & $8.0^{\mathrm{a}}$ & $5.5^{\mathrm{abc}}$ & $3.87^{\mathrm{bc}}$ & $6.2^{\mathrm{ab}}$ & $3.2^{\mathrm{bc}}$ \\
\hline No.feather interned & FIL & $3.7^{\mathrm{bc}}$ & $4.7^{\mathrm{ab}}$ & $3.0^{\text {cd }}$ & $4.2^{\mathrm{abc}}$ & $4.50^{\mathrm{ab}}$ & $5.50^{\mathrm{a}}$ & $3.75^{\mathrm{bc}}$ & $4.00^{\mathrm{bc}}$ & $1.75^{\mathrm{d}}$ \\
\hline Feather internode & $\mathrm{NN}$ & $1.67^{\mathrm{ab}}$ & $1.75^{\mathrm{ab}}$ & $0.97^{\mathrm{b}}$ & $1.17^{\mathrm{ab}}$ & $2.02^{\mathrm{ab}}$ & $1.10^{\mathrm{b}}$ & $1.40^{\mathrm{ab}}$ & $1.32^{\mathrm{ab}}$ & $2.50^{\mathrm{a}}$ \\
\hline Inflorescence length & IL & $3.5^{\mathrm{a}}$ & $2.5^{\mathrm{bc}}$ & $2.4^{\mathrm{bc}}$ & $3.1^{\mathrm{ab}}$ & $0.50^{\mathrm{d}}$ & $3.2^{\mathrm{ab}}$ & $3.8^{\mathrm{a}}$ & $3.5^{\mathrm{a}}$ & $1.9^{\mathrm{c}}$ \\
\hline inflorescence width & IW & $0.75^{\mathrm{b}}$ & $0.55^{\text {bc }}$ & $0.30^{\mathrm{c}}$ & $0.35^{\mathrm{c}}$ & $0.25^{\mathrm{c}}$ & $1.52^{\mathrm{a}}$ & $0.32^{\mathrm{c}}$ & $0.52^{\mathrm{bc}}$ & $0.42^{\mathrm{c}}$ \\
\hline inflorescence length/width & LS & $8.63^{\mathrm{abc}}$ & $4.85^{\mathrm{bcd}}$ & $8.08^{\mathrm{abc}}$ & $9.41^{\mathrm{ab}}$ & $4.15^{\mathrm{d}}$ & $2.30^{\text {cd }}$ & $12.18^{\mathrm{a}}$ & $6.80^{\mathrm{abc}}$ & $4.98^{\mathrm{bcd}}$ \\
\hline No. flower & $\mathrm{NF}$ & $3.25^{\mathrm{c}}$ & $9.25^{\mathrm{b}}$ & $4.00^{c}$ & $5.00^{\mathrm{c}}$ & $3.45^{\mathrm{c}}$ & $15.25^{\mathrm{a}}$ & $5.25^{\mathrm{c}}$ & $5.25^{\mathrm{c}}$ & $6.00^{\mathrm{c}}$ \\
\hline
\end{tabular}

\footnotetext{
${ }^{\text {abcd }}$ different superscripts refer to significant differences, $\mathrm{P}<0.05$
} 
Results showed that the highest values for five out of the seven growth characters (shoot length, node number, internode length, number of feather shoot, feather shoot length) were recorded for the cultivar Coratina. Koroneiki had the highest leaf width, dry inflorescence width, and several flowers. Interestingly, it showed the lowest records for inflorescence length/width comparing to the other cultivars under study. Leaf characters, except for the width, were higher for the cultivar Kalamata. However, Kalamata showed the lowest number of feather shoots. The highest number of feather internode was recorded for the cultivar Picual, while the lowest was recorded for Manzanillo. It worth mentioning that, Ageezi Shami had the lowest leaf area and fresh weight records. The lowest value of Dry weight Shoot length and Internode length was recorded in 4 . Thus, the olive trees included in the study could be discriminated against and identified using 17 traits used.

These results are in agreement with that of Fayek 2014 who reported that Coratina had longer inflorescence and higher flower percentage when compared with some Egyptian clones and Coratina and Koroneiki. Similarly, Sayed, (2013) found variation in the length of inflorescence in 10 imported olive cultivars. Moreover, Sorkheh and Khaleghi (2016) discriminated against and identified their studied olive trees using 18 traits. Also, Sheidai et al. (2010) used 24 morphological characters to compare between 8 brown olive populations of Iran.

\section{Genotype Identification by ISSR}

ISSR marker is proven to be a highly polymorphic marker even between closely related genotypes since the non-coding DNA region lacks functional genetic constraints (Nahla et al.2014). Interestingly, we obtained a reproducible twelve ISSR primers out of twenty-four initially tested. A representative Figure representing ISSR is shown in Figure (1). Also, Essadki et al. (2006) reported that out of the 13 primers tested with Moroccan olive cultivars, only four primers revealed polymorphic and reproducible results. Moreover, Lopes et al. 2007 selected 17 ISSR primers out from 100 primers tested with 38 olive genotypes. In this study, a total of 197 bands were generated by the 12 primers selected; 163 of them were polymorphic. The mean number of bands was 16.4/primer and band sizes ranged from $200 \mathrm{bp}$ to $2590 \mathrm{bp}$. That is in agreement with that obtained by Lopes et al 2007 who used 17 ISSR primers and amplified 204 bands, of which 180 were polymorphic between 38 Portuguese olive cultivars. Also, Gomes et al. (2009) obtained 135 reproducible bands including 108 polymorphic ones. However, they only used eleven ISSR primers amplified. Also, Kaya, E. et al. 2015 used 10 ISSR primers and obtained a total of 217 bands, 206 of which were polymorphic among 40 clones belonging to 8 Turkish cultivars.

The highest number of bands recorded in this study (22) was that amplified by primer ISSR 03, whereas the lowest one (12) was that revealed by primers (ISSR 11, ISSR 12, ISSR 14, and ISSR 16) as presented in Table 3. The level of polymorphism obtained by the ISSR marker ranged from 66.7 (for ISSR 04) to $94.4 \%$ (for ISSR 02) with an average of $82.74 \%$. The latter result is in agreement with that previously ranged from $79 \%$ (Gomes et al. 2009); 88\% (Lopes et al 2007); 91.8\% (Zhan et al 2015) and 94.9\% (Kaya et al., 2015). 
Table 3: ISSR primers used for DNA amplification; their corresponding sequences; the total number of bands; a number of polymorphic bands and the percentage (\%) of polymorphism.

\begin{tabular}{|l|l|l|l|l|}
\hline $\begin{array}{c}\text { Primer } \\
\text { Name }\end{array}$ & \multicolumn{1}{|c|}{ Primer sequence $\left(\mathbf{5}^{\prime} \rightarrow \mathbf{3}^{\prime}\right)$} & $\begin{array}{l}\text { Total } \\
\text { Bands }\end{array}$ & $\begin{array}{c}\text { Polymorphic } \\
\text { bands }\end{array}$ & $\begin{array}{c}\text { Polymorphic } \\
\text { Bands }(\boldsymbol{\%})\end{array}$ \\
\hline ISSR01 & AGAGAGAGAGAGAGAGYC & 16 & 15 & 93.8 \\
\hline ISSR 02 & AGAGAGAGAGAGAGAGY & 18 & 16 & 94.4 \\
\hline ISSR 03 & ACACACACACACACACYT & 22 & 20 & 90.5 \\
\hline ISSR04 & ACACACACACACACACYG & 18 & 12 & 66.7 \\
\hline ISSR 05 & GTGTGTGTGTGTGTGTYG & 18 & 16 & 88.9 \\
\hline ISSR 06 & CGCGATA GATAGATAGATA & 14 & 13 & 92.9 \\
\hline ISSR 11 & ACACACACACACACACYA & 15 & 12 & 80 \\
\hline ISSR 12 & ACACACACACACACACYC & 15 & 12 & 80 \\
\hline ISSR 13 & AGAGAGAGAGAGAGAGYT & 18 & 13 & 72.2 \\
\hline ISSR 14 & CTCCTCCTCCTCCTCTT & 15 & 12 & 80 \\
\hline ISSR 16 & TCTCTCTCTCTCTCTCA & 13 & 12 & 92.3 \\
\hline ISSR 18 & HVHCACACACACACACAT & 15 & 11 & 73.3 \\
\hline TOTAL & & 197 & 163 & 82.74 \\
\hline
\end{tabular}

$* \mathrm{Y}=(\mathrm{C}$ or $\mathrm{T})$

$\mathrm{H}=\operatorname{not} \mathrm{G}(\mathrm{A}$ or $\mathrm{C}$ or $\mathrm{T})$

$\mathrm{V}=\operatorname{not} \mathrm{T}(\mathrm{A}$ or $\mathrm{C}$ or $\mathrm{G})$

\section{Genotype Identification by SCoT}

SCoT marker has several advantages over many marker techniques in evaluating the genetic characteristics: no prior sequence information is needed as that required by SSR, higher reproducibility than RAPD and it is relatively lower in cost than AFLP. The SCoT technique emerged in 2009, and few studies are available for different plant species.

Out of 36 SCoT primers initially tested, thirteen primers were further chosen to examine genetic polymorphism among the nine olive cultivars. They successfully produced a total of 242 clear bands (Fig. 1), with an average of 18.6 bands per primer (Table 3 ). The overall size of amplified bands ranged from 200 to 2320 bp. While primers SCoT2, SCoT11, and SCoT 22 revealed percentages of $94.7,88.9$, and $94.1 \%$ respectively, 10 primers showed $100 \%$ polymorphism. These 10 primers showing high allelic variation can be used to study genetic polymorphism as well as to fingerprint olive genotypes. Nevertheless, Moreover,
Amirmoradi et al. 2012 generated a polymorphism that reached $100 \%$ working on 38 accessions of Cicer species. They obtained a total number of 112 bands with an average number of 12.4 bands per primer ranging in size from 220 to $2250 \mathrm{bp}$.

In this study, primer (SCoT 03) yielded the highest number of bands (31), while the lowest number (12) was detected by primers SCoT 4, SCoT 33, and SCoT 36 . The number of polymorphic bands was 236 bands with an average of 18.2 bands/ primer. This high average polymorphism rate obtained $(97.52 \%)$ from studying the 9 olive cultivars is quite similar to that reported by Bhattacharyya 2013 (96.21\%); Leila Alikhan et al. 2014 (95.71\%); and El framawy 2016 $(97.10 \%)$ revealing the elevated level of variability when compared with similar studies. Interestingly, lower polymorphism rates were recorded by Gorji et al., 2011 (61\%); Shahlaei et al., 2014 (36.14\%); Xiong et al., 2011 (38.22\%). That would be attributed to the differences in genotypes and species tested. 
Table (4): SCoT primers used in this study, their corresponding sequences, the total number of bands, number of polymorphic bands, and the percentage of polymorphism.

\begin{tabular}{|c|l|l|l|l|}
\hline $\begin{array}{c}\text { Primer } \\
\text { Name }\end{array}$ & ${\text { Primer sequence }\left(\mathbf{5}^{\prime} \rightarrow \mathbf{3}^{\prime}\right)}^{\mathbf{P}^{\prime}}$ & $\begin{array}{l}\text { Total } \\
\text { Bands }\end{array}$ & $\begin{array}{l}\text { Polymorphic } \\
\text { bands }\end{array}$ & $\begin{array}{l}\text { Polymorphic } \\
\text { Bands } \mathbf{( \% )}\end{array}$ \\
\hline SCoT 02 & CAACAATGGCTACCACCC & 19 & 18 & 94.7 \\
\hline SCoT 03 & CAACAATGGCTACCACCG & 31 & 31 & 100 \\
\hline SCoT 04 & CAACAATGGCTACCACCT & 12 & 12 & 100 \\
\hline SCoT 05 & CAACAATGGCTACCACCC & 26 & 26 & 100 \\
\hline SCoT 11 & AAGCAATGGCTACCACCA & 18 & 16 & 88.9 \\
\hline SCoT 13 & ACGACATGGCGACCATCG & 21 & 21 & 100 \\
\hline SCoT 16 & ACCATGGCTACCACCGAC & 17 & 17 & 100 \\
\hline SCoT 20 & ACCATGGCTACCACCGCG & 19 & 19 & 100 \\
\hline SCoT 22 & AACCATGGCTACCACCAC & 17 & 16 & 94.1 \\
\hline SCoT 28 & CCATGGCTACCACCGCCA & 19 & 19 & 100 \\
\hline SCoT 33 & CCATGGCTACCACCGCAG & 12 & 12 & 100 \\
\hline SCoT 35 & CATGGCTACCACCGGCCC & 19 & 19 & 100 \\
\hline SCoT 36 & GCAACAATGGCTACCAC & 12 & 12 & 100 \\
\hline Total & & 242 & 236 & 97.52 \\
\hline
\end{tabular}

\section{Genotype Identification by RAMP}

Twenty primer combinations $($ RAPD primer $\times$ ISSR primer) were tested for their ability to characterize the studied olive cultivars and to investigate the genetic relationships among them, out of these, eleven primer combinations (PC) (Table 5) produced clear and reproducible banding profile with a product size that ranged between 150-1200 bp. These RAMP primer combinations yielded a total of 172 bands, with an average of 15.6 bands per primer. The number of bands varied from 10 (PC 06) to 20 (PC 03 and PC 08) with an average of 15.63 bands per primer. Out of the 172 bands obtained, 140 (81.39\%) were polymorphic. The highest number of polymorphic bands (18 bands) was that amplified with PC 03, while the lowest one (5) was obtained with PC 06 with an average of 12.72 bands per primer. In this context, Soumaya et al. (2011) obtained 210 reproducible bands as RAMPs using 18 primer combinations to study 40 Tunisian date-palm cultivars with a polymorphism percentage of 88.57. Moreover, Rai et al., 2013 used 17 RAMP PCs and they obtained 106 fragments; 87 out of them were polymorphic when studying 48 Capsicum genotypes. The number of fragments per primer combination ranged from three to nine with an average of five fragments per primer combination. Also, Saleh 2015 used 21 RAMP (PCs) that could distinguish 145 loci, 139 of which (95.862\%) were polymorphic in three genotypes of Arthrocnemum macrostachyum. 
Table 5: RAMP primers used, their corresponding sequences, the total number of bands, number of polymorphic bands, and \% polymorphism.

\begin{tabular}{|c|c|c|c|c|c|}
\hline & $\begin{array}{c}\text { Primer } \\
\text { combination } \\
(\mathrm{PC})\end{array}$ & Primer sequence $\left(5^{\prime} \rightarrow 3^{\prime}\right)$ & $\begin{array}{l}\text { Total } \\
\text { Bands }\end{array}$ & $\begin{array}{c}\text { Polymorphic } \\
\text { Bands }\end{array}$ & $\begin{array}{c}\text { Polymorphic } \\
\text { Bands (\%) }\end{array}$ \\
\hline PC01 & ISSR02/ OPA 10 & (AG)8 YG/GTGATCGCAG & 16 & 15 & 93.75 \\
\hline $\mathrm{PC} 02$ & ISSR03/ OPA 10 & (AC)8YT / GTGATCGCAG & 16 & 16 & 100 \\
\hline PC03 & ISSR04/ OPA 10 & (AC)8YG / GTGATCGCAG & 20 & 18 & 90.0 \\
\hline $\mathrm{PC} 04$ & ISSR14/ OPZ 09 & (CTC)5TT / CACCCCAGTC & 19 & 12 & 63.16 \\
\hline $\mathrm{PC} 05$ & ISSR18/ OPZ 09 & HVH(CA)7AT / CACCCCAGTC & 16 & 10 & 62.50 \\
\hline PC06 & ISSR19/ OPZ 09 & HVHT(CCT)4CC/CACCCCAGTC & 10 & 5 & 50.0 \\
\hline PC07 & ISSR20/ OPZ 09 & HVHT(GT)7/ CACCCCAGTC & 14 & 14 & 100 \\
\hline PC08 & ISSR06/ OPB10 & CGC (GATA)4 / CTGCTGGGAC & 20 & 16 & 80.0 \\
\hline PC09 & ISSR08/ OPC4 & (AGAC)4 GC / CCGCATCTAC & 14 & 12 & 85.71 \\
\hline PC10 & ISSR10/ OPC07 & (GACA)4 AT/ GTCCCGACGA & 15 & 13 & 86.66 \\
\hline \multirow[t]{2}{*}{ PC11 } & ISSR12/ OPC08 & (AC)8YC/ TGGACCGGTG & 12 & 9 & 75.0 \\
\hline & Total & & 172 & 140 & 81.39 \\
\hline
\end{tabular}
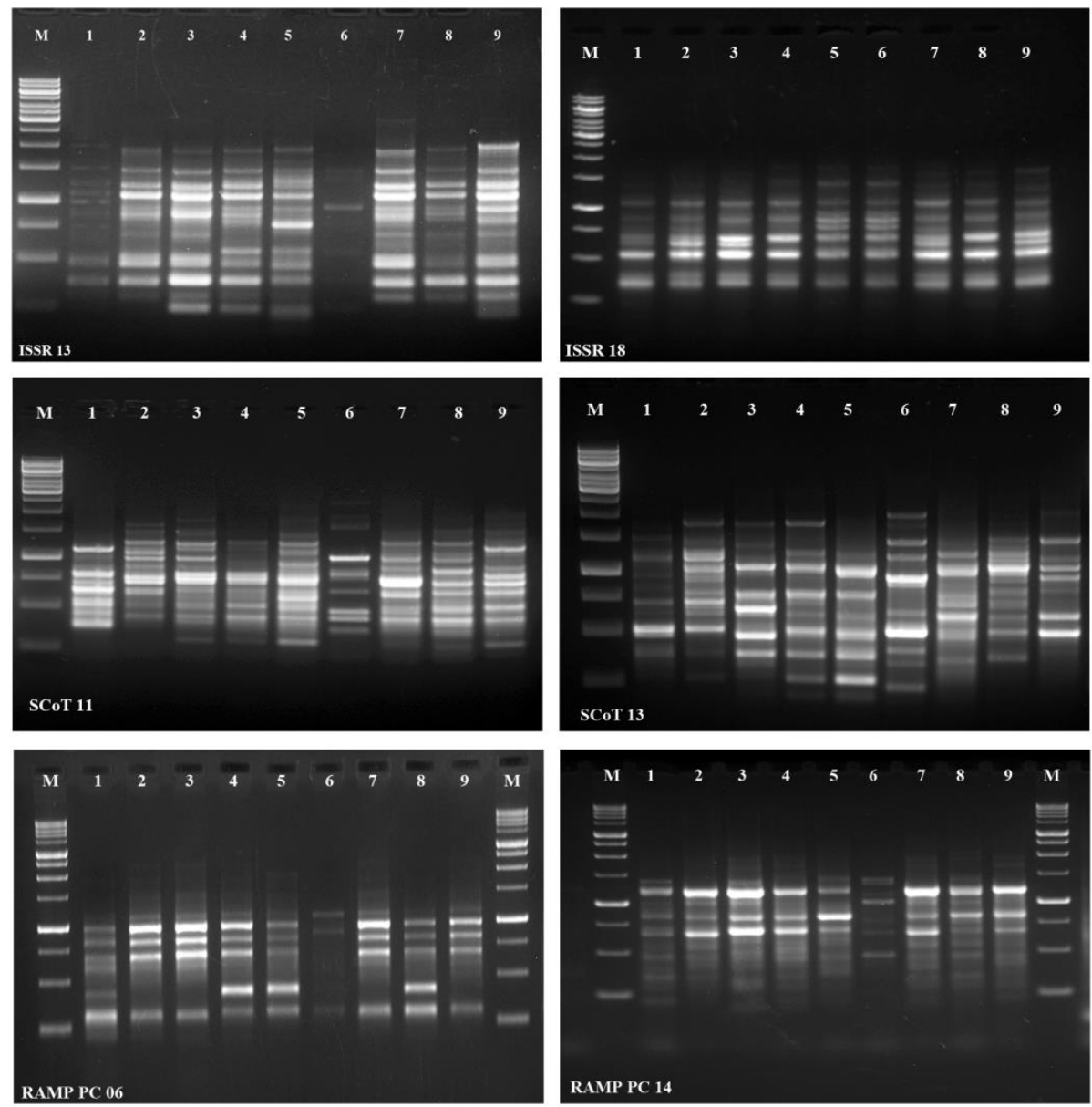

Figure (1): representative figure showing the polymorphism as revealed by ISSR marker; (ISSR 13 \& ISSR18), SCoT marker (primers SCoT 11 and SCoT 13) and by RAMP primer combinations (PC06 \&PC14) in the olive cultivars studied M: $1 \mathrm{~kb}$ DNA size marker. Numbers refer to the corresponding olive cultivars as indicated in Table (1). 
Genetic relationships and differentiation among olive cultivars

Estimated genetic similarity based on morphological data revealed that the closest cultivars to be Manzanillo and Frantoio followed by Kalamata and Picual. On the other hand, Frantoio and Coratina showed the lowest similarity between the studied cultivars. However, genetic similarities based on ISSR, SCoT, and RAMP data were showed a different trend; the Egyptian cultivars (Teffahi and Ageezi Shami) gave the highest genetic similarity (0.81) developed by ISSR data, (0.78) by RAMP data, and (0.71) combined data among studied cultivars. Moreover, SCoT data revealed the highest genetic similarity (0.62) between varieties Frantoio and Ageezi Shami. The least genetic similarity was that recorded between cultivars Ageezi Shami and krownaki by ISSR, and RAMP and with the dendrogram constructed using the combined data $(0.47$, 0.54 , and 0.48 respectively). On the other hand, SCoT recorded the lowest genetic similarity $(0.38)$ between Manzanillo and Koroneiki. It worth mentioning that, the high diversity recorded between Egyptian and foreign genotypes understudy would be the diverse germplasm origin resulting from crosses between wild olive and cultivated one over through the Mediterranean region. In this context, El Saied et al., 2012 reported a high degree of genetic similarities among the Egyptian cultivars based on ISSR marker, on the contrary to the foreign cultivars. Also, Fayek et al 2014 reported the highest genetic similarity for the ISSR marker of (0.75) between two different Egyptian genotypes (Maraki and Sewia) and the least genetic similarity (0.40) between Coratina and Kronakiei. Also, Lopes (2007) reported a genetic similarity that ranged from 0.55 to 0.84 for 38 Portuguese olive cultivars based on ISSR data. As in the case of SCoT data, similar results to those previously reported in studies of different species (Xiong et al., 2011; Gorji et al. 2012; Shahlaei et al., 2014; Zhang et al. 2015 El Framawy 2016) While, Pu et al.,2009 scored the mean genetic similarity of 0.803 for barley using RAMP data. Similarly, Soumaya et al. (2011) reported that genetic similarity ranged from 0.10 to 0.76 with a mean of 0.34 for date-palm genotypes by RAMP data.

The derived UPGMA dendrogram based on the similarity matrices for ISSR, SCoT, RAMP and that constructed using combined data (Figure 2 ) illustrate the affinities among the nine cultivars and is composed of two main clusters within three main groups.

Morphological data separated Coratina into the distinct cluster with leaving the 8 remaining cultivars to form two groups in the second cluster. The first group is composed of cultivars Chemlali, Manzanillo, Frantoio, and Teffahi. Interestingly cultivars Manzanillo and Frantoio were the closest. Moreover, the last group contained cultivars Ageezi Shami, Koroneiki, Kalamata, and Picual. This finding is congruent with the results of Zhan et al., 2015 who found that Coratina were clustered in one independent group and Koroneiki and Chemlai were in another sub-group when analyzing 32 olive cultivars using SSR and ISSR markers. On the other hand, Koroneiki was separated into a singular cluster by SCoT marker and combined data program. However, the cultivar Koroneiki was added to the group of Frantoio and Coratina in the first cluster by ISSR marker, but Frantoio and Coratina successfully were clustered together in the dendrogram of the combined data. Montemurro et al. (2005) reported the same trend of grouping between the Italian Frantoio and Coratina varieties by using the UPGMA dendrogram from data with AFLP and SSR markers. The high similarity coefficients recorded reference to the existence of a common ancestor for the study cultivars.

Remarkably, the Egyptian cultivars, Teffahi, and Ageezi Shami tend to form a separate group by RAMP markers; the case was further confirmed by the combined dendrogram. Moreover, the RAMP marker successfully separated Chemlali, Kalamata, koroneiki, and Coratina in the second group and the last group comprising Manzanillo, Frantoio, and Picual. 
Additionally, Chemlali, Kalamata were clustered together in the dendrogram of the combined data.

These discrepancies in the genetic similarity revealed by the different marker types could be attributed to the different mechanism of detecting the polymorphism and genome coverage offered by each marker.
Therefore, the genetic similarity based on the combined data could be more representative of the genetic relationships. In general, such findings were previously reported (Lopes et al., 2007\& Sorkhen and Khaleghi, 2016).

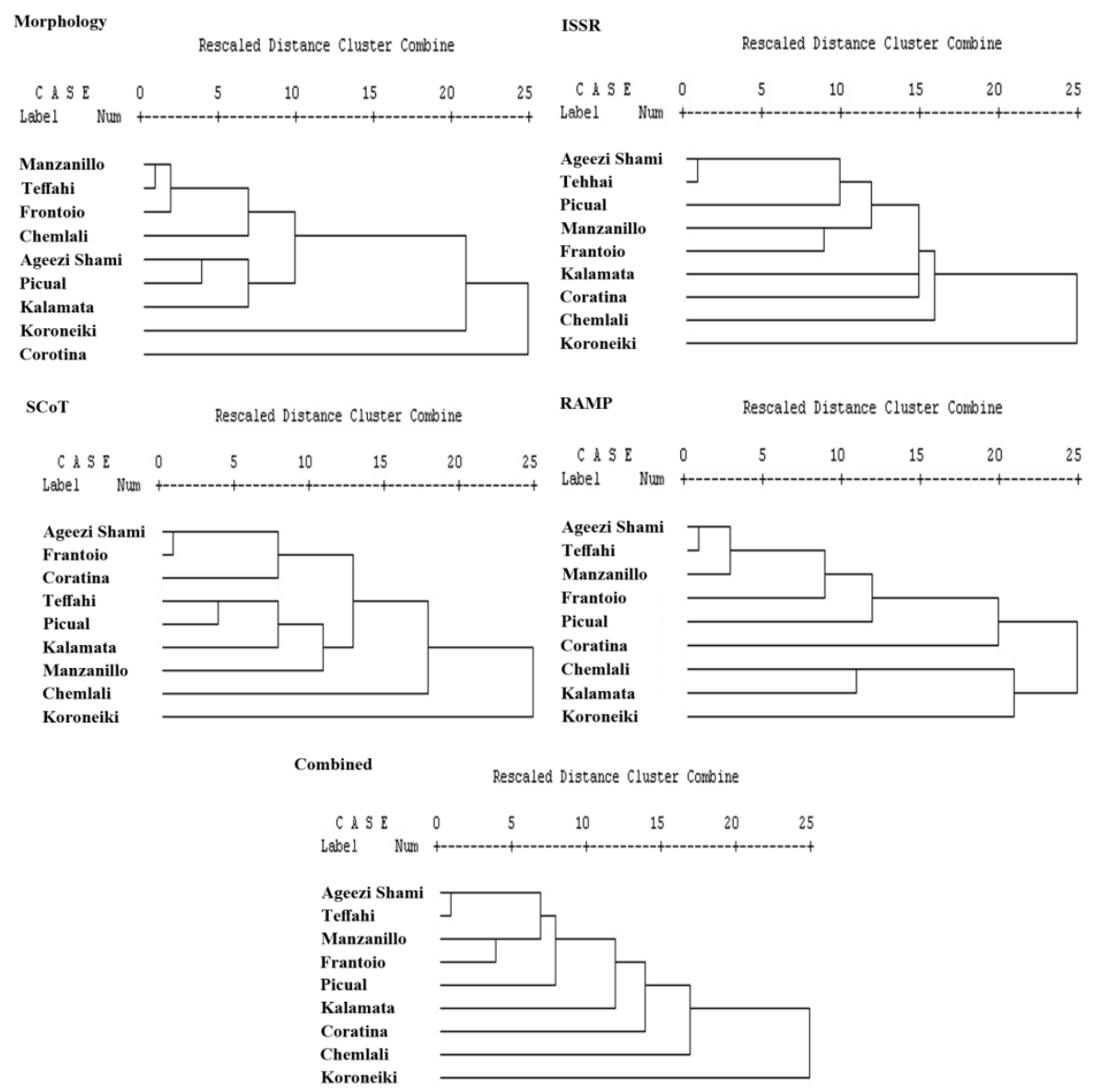

Figure 2: UPGMA dendrogram derived from genetic similarity between nine olive cultivars, based on morphological traits and amplification profiles produced y ISSR, SCoT, and RAMP

A comparison of distance matrices of morphological and molecular data was carried out based on the correlation coefficient of the Mantel test to evaluate the degree of correspondence (Table 6). In this study, no significant correlation was found between matrices based on qualitative traits and the three markers used. On the contrary, ISSR \& SCoT gave the most significant correlation $(r=0.57)$ compared to ISSR \& RAMP ( $\mathrm{r}=0.47)$ and RAMPO and SCoT ( $\mathrm{r}=0.48)$.
Accordingly, Sorkheh and khaleghi, 2016 reported no significant correlation between matrices based on SSR markers and qualitative traits or between matrices based on SSR markers and quantitative traits among 20 Turkish olive trees. On the other hand, Zaher, H., (2011) identified a significant correlation between morphological and microsatellite marker-derived matrices derived by Mantel test analysis. 
Table (6): correlation between morphological traits and molecular markers

(ISSR, SCoT, and RAMP) based on the Mantel test

\begin{tabular}{|l|l|l|l|}
\hline Distance A & Distance B & Correlation & P-Value \\
\hline RAMP Frequency & ISSR Frequency & 0.467 & 0.002 \\
\hline SCoT Frequency & ISSR Frequency & 0.573 & 0.0008 \\
\hline SCoT Frequency & RAMP Frequency & 0.475 & 0.004 \\
\hline SCoT & morphology & 0.3829 & 0.121 \\
\hline ISSR & morphology & 0.283 & 0.142 \\
\hline RAMP & morphology & 0.2507 & 0.137 \\
\hline
\end{tabular}

\section{Comparison}

Three different PCR-based markers (ISSR, SCoT, and RAMP) in this study allowed a better comparison to the effectiveness of each genetic marker in the characterizing of olive cultivars. These markers successfully provided a unique fingerprint for each of the olive varieties used. 12 ISSR primers, 13 SCoT primers, and 11 RAMP primer combinations successfully produced a total of 197, 242, and 172 reproducible bands, with a percentage of polymorphism of $82.74 \%, 97.52 \%$, and $81.39 \%$ respectively (Table 7)

The high polymorphism generated by these markers indicates that the olive tree is a highly polymorphic species that reflect the agronomic diversity within olive cultivars. These results are following previous studies that carried out for olive trees reported by MartinsLopes et al. 2007; Gomes et al. 2009; Ben Mohamed et al. (2016) SORKHEH and KHALEGHI 2016

The discriminatory power and the usefulness of each marker were evaluated by comparing its PIC and MI values. The highest value of polymorphism was that recorded by SCoT marker with a PIC value of (0.31) and MI (5.63) compared to ISSR and SCoT which indicates that these loci were highly informative for olive cultivars studied, based on Botstein et al. (1980)who mentioned the primers that show a PIC value of $0.5 \geq \mathrm{PIC} \leq 0.25$ is considered informative marker. So SCoT marker can be used as an effective complementary method besides ISSR and RAMP for molecular characterization of olive as well as for determination of genetic relationships. This finding concurs with the report by Gorji et al. 2011 reported that SCoTs markers were more informative and efficient for fingerprinting of Potato varieties than other markers based on the average percentage polymorphism, PIC, and overall Shannon index. Also, Leila Alikhan et al. 2014 who found SCoT markers were more informative than IRAP and ISSR for the assessment of diversity among individuals which had the highest PIC value (0.38) compared to ISSR (0.30) and IRAP $(0.32)$ respectively.

On the contrary, Noor Zafirah Ismail 2016 reported a high value of PIC of 0.25 , MI 11.36 from RAMP markers comparing between RAPD and ISSR although both markers showed $100 \%$ polymorphisms whereas RAMP markers detected $86 \%$ polymorphism for clinecanthus nutans

Also, in this work Na (1.96 \pm 0.18$),$ EMR (18.15), and SI $(0.48 \pm 0.16)$ were quite high in SCoTc compared to ISSR, and RAMP. The effective number of alleles (Ne) of ISSR, SCoT, and RAMP showed less variability than $\mathrm{Na}$ with an average of $1.45 \pm 0.36$ for the different markers used. Consequently, these results are in agreement with previous studies Noor Zafirah Ismail 2016; Mahnaz Nezamivand CHEGINI et al 2016and Guo 2012 in which PIC, EMR, and MI can be anticipated as most marker parameters for selecting informative markers. 
Table (7): a comparison of the efficiency of ISSR SCoT and RAMPO to characterize the nine olive germplasm based on polymorphism parameters used in this study

\begin{tabular}{llll}
\hline \multirow{2}{*}{ Parameter } & \multicolumn{3}{c}{ Marker Name } \\
\cline { 2 - 4 } Number of assays screened & ISSR & SCoT & RAMPO \\
Total loci screened & 12 primers & 13 primers & $\begin{array}{l}11 \text { primer } \\
\text { combinations }\end{array}$ \\
Multiplex ratio (MR) & 197 & 242 & 172 \\
Total number of polymorphic loci & 14.9 & 18.6 & 15.6 \\
Polymorphism \% per assay & $82.74 \%$ & $97.52 \%$ & 81.39 \\
No. of observed alleles (Na) & $1.83 \pm 0.37$ & $1.96 \pm 0.18$ & $1.72 \pm 0.44$ \\
No. of effective alleles (Ne) & $1.45 \pm 0.33$ & $1.45 \pm 0.33$ & $1.45 \pm 0.36$ \\
Shannon index (I) & $0.41 \pm 0.23$ & $0.48 \pm 0.16$ & $0.39 \pm 0.27$ \\
Effective multiplex ratio (EMR) & 13.58 & 18.15 & 12.72 \\
Polymorphic information content & 0.26 & 0.0 .31 & 0.26 \\
(PIC) mean & & 5.63 & 3.31 \\
Marker index (MI) mean & 3.53 & & \\
\hline
\end{tabular}

Results indicated that the SCoT marker can be used as an effective complementary method to ISSR and RAMP because SCoT is a gene-targeted marker and can effectively produce makers linked with traits and could be employed in studying genetic relationships. Moreover, results can asset in establish a molecular database for Egyptian olive identification and to construct a molecular catalog that can compare the molecular pattern of cultivars as well as to avoid redundant genetic entities to make a reference collection

\section{Conclusion}

Molecular markers are still the most important and most efficient markers to study the variability and genetic relationships between different plant species. ISSR, SCOT, and RAMP markers are powerful tools for olive varietal identification as well as in enabling an accurate characterization of the nine cultivars examined. Thus, it would serve in establishing a molecular database for Egyptian olive identification and to construct an accurate molecular map for olive cultivars. Moreover, it would represent a better understanding of the diversity available in the Egyptian olive cultivations in one of the most threatened areas in
EL Arish governorate, Egypt. Results obtained can through light for reliable olive breeding and conservation strategies in Egypt.

\section{REFERENCES:}

Amirmoradi B., Talebi R. and Karami E. 2012 Comparison of genetic variation and differentiation among annual Cicer species using start codon targeted (SCoT polymorphism, DAMD-PCR, and ISSR markers. Plant Syst. Evol. 298, 1679-1688.

Belaj A, Leon L, Satovic Rosa R (2011). Variability of wild olives (Oleaeuropaea subsp. europaea var. sylvestris) analyzed by agro-morphological traits and SSR markers. SciHortic 129:561-569.

Bhattacharyya, P., Kumaria, S., Kumar, S., Tandon, P., 2013. Start Codon Targeted (SCoT) marker reveals genetic diversity of DendrobiumnobileLindl., an endangered medicinal orchid species. Gene 529, 21-26

Botstein D., White R. L., Skolnick M. and Davis R. W. 1980 Construction of a genetic linkage map Inman 
using restriction fragment length polymorphisms. Am. J. Hum. Genet. 32, 314-331.

\section{COI (ConseilOléicole International)}

(1997)

Méthodologie de caractérisationprimaire des varieties deliver. Projetsurlaconservation, caractérisation, collected et utilisationderessourcesgénétiques de l'Olivier, (RESGEN-T96/97), Union EuropéenneConseilOléicole International, Madrid, España Dice, L. R. 1945.Measures of the amount of ecologic association between species. Ecology, 26: 297-302.

Collard, B.C.Y., Mackill, D.J., 2009. Start codon targeted (SCoT) polymorphism: a simple, novel DNA marker technique for generating gene-targeted markers in plants. Plant Mol. Biol. Report. 27, 86-93.

Elframawy, A., Deif, H. and El-Bakatoushi, R. (2016) Genetic Variation among Fragmented Populations of Atriplexhalimus L. Using Start Codon Targeted (SCoT) and ITS1-5.8S-ITS2 Region Markers. American J

Essadki, M., Ouazzani, N., Lumaret, R., Moumni, M. (2006).ISSR variation in olive-tree cultivars from Morocco and other Western Countries of the Mediterranean Basin. Genetic Resources and Crop Evolution, 53: 475-482 http://dx.doi.org/10.1007/s10722-004-1931-8

Fayek, M.A., Abdel-Mohsen, M.A., Laz, S.I., and El- Sayed, M. E. (2014) Morphological, Agronomical and Genetic Characterization of Egyptian Olive Clones Compared with the International Cultivars. Egypt. J.Hort ., 41, 59- 82.

\section{Gomes S, Martins-Lopes P, Lopes J, Guedes-Pinto} H (2009) Assessing genetic diversity in Oleaeuropaea L. using ISSR and SSR markers. Plant Mol. Biol. Rep.27, 365-373

Gorji, A.M., Poczai, P., Polgar, Z., Taller, J., 2011. The efficiency of arbitrarily amplified dominant markers (SCoT, ISSR, and RAPD) for diagnostic fingerprinting in tetraploid potato. Am. Potato J. 88 (3), 226-237

Guo, D.L., Zhang, J.Y., Liu, C.H., 2012. Genetic diversity in some grape varieties revealed by SCoT analyses. Mol. Biol. Rep. 39, 5307-53134

Grati-Kamoun N, Mahmoud F, Rebaï A, Gargouri A. Genetic diversity of Tunisian olive tree (Olea Europaea L.) cultivars assessed by AFLP markers. Genet Resour Crop Evol. 2006;53:265-275.

Hamidi H, Talebi R, Keshavarzi F. Comparative efficiency of functional gene-based markers, start codon targeted polymorphism (SCoT), and conserved DNA-derived polymorphism (CDDP) with ISSR markers for diagnostic fingerprinting in wheat (Triticumaestivum L.). Cereal ResCommun.2014;42(4):558-567.

Hannachi H, Catherine B, Monji M, Salem H, Mohamed G, Andre B. Difference between native and introduced olive cultivars as revealed by the morphology of drupes, oil composition, and SSR polymorphisms. SciHortic. 2008;116:280-290

Hartl, D. L., and A. G. Clark (1989). Principles of Population Genetics, 2nd ed. Sunderland, MA: Sinauer Associates.

Hegazi S, Hegazi A, Tawfik A, Sayed H (2012) Molecular characterization of local and imported olive cultivars grown in Egypt using ISSR technique. J. Hort. SciOrnam. Plants 4 (2), 148-154.

Jiang, L.F.; Qi, X.; Zhang, X.Q.; Huang, L.K.; Ma, X.; Xie, W.G. (2014). Analysis of diversity and relationships among orchardgrass (Dactylisglomerata L.) accessions using start codon-targeted markers. Genet.Mol. Res., 13, 4406-44.

KAYA, E. and E. YILMAZ-GÖKDOĞAN (2015). Molecular Characterization Of Some Turkish Olıve Cultivars Using Random Amplified Polymorphic DNA 
(RAPD) Markers. Journal of Natural and Applied Science.19(1), 103-106, 2015.

Le Cunff, L., Fournier-Level, A., Laucou, V., Vezzulli, S., Lacombe, T., Adam-Blondon, A.F., Boursiquot J.M., and P. 2008. Construction of nested genetic core collections to optimize the exploitation of natural diversity in Vitisvinifera L. subsp. Sativa. BMC Plant Biol. 8:31

Luo, C., He, X., Chen, H., Ou, S., Gao, M., 2010. Analysis of diversity and relationships among mango cultivars using Start Codon Targeted (SCoT) markers.Biochem. Syst. Ecol. 38 (6), 1176-118

Mantel NA (1967) The detection of disease clustering and a generalized regression approach. Cancer Res 27: 209-220

Martins-Lopes, P., J. Lima-Brito, S. Gomes, J.Meirinhos, L. Santos, and H. Guedes-Pinto. 2007. RAPD and ISSR molecular markersinOleaeuropaea L.: Genetic variability and molecular cultivar identification. Gen. Resour. Crop Evol. 54(1):117-128

\section{Montemurro, C; R. Simeone, A. Pasqualone, E}

Ferrara, A Blanco. Genetic relationships and cultivar identification among 112 olive accessions using AFLP and SSR markers. The Journal of Horticultural

Science and Biotechnology 80 (1), 105-110

Muzzalupo, I., Vendramin, G. G., and Chiappetta, A. (2014). Genetic biodiversity of Italian olives (Olea europaea) germplasm analyzed by SSR markers. Sci. World J. 2014:296590. DOI: 10.1155/2014/296590

Nahla A. El-Sherif, Amina A. Mohamed, M.A. Saad, HodaBarakat, and Sara Aly (2014).Genetic variation in Egyptian white Lupin (Lupinusalbus L.)genotypes based on combined data of ISSR and fluorescence-based AFLP markers.Egypt. J. Genet. Cytol.,43:1-23
Noormohammadi Z., Farahani Y. H.-A., Sheidai M., Ghasemazaden- Baraki S. \&Alishah O. 2012. Development of RAMPO marker for assessment of genetic diversity in tetraploid cotton genotypes. Gene Conserve 11: 1-11

Parra-Lobato MC, Delgado-Martinez FJ, GomezJimenez MC (2012) Morphological traits and RAPD markers for characterization and identification of minor Spanish olive cultivars from the Extremadura region. Genet Mol Res. 11:2401-2411.

Powell W., Morgante M., Andre C., Hanafey M., Vogel J., Tingey S. \&Rafalski A. 1996.The comparison of RFLP, RAPD, AFLP, and SSR (microsatellite) markers for germplasm analysis. Molecular Breeding 2: 225-238

Richards CM, Volk GM, Reeves PA, Reilley AA, Henk D, ForslinePL, Aldwinckle HS (2009) Selection of stratified core sets representing wild apple (Malus sieversii). J Am Soc Hort Sci134:228-235

Rebai A (2008) Characterization and identification of Tunisian olive tree varieties by microsatellite markers. HortSci 43: 1371-1376

Richards, L.A. (1954) Diagnosis and Improvement of Saline and Alkali Soils. US Department of Agriculture, Handbook No. 60, Washington DC

Rohlf, F.J. (2002) NTSYS-pc: Numerical Taxonomy System ver.2.1. Exeter Publishing Ltd., Setauket, New York.

Saleh B (2015) Phylogenetic assessment of Arthrocnemum macrostachyum (Chenopodiaceae) genotypes using RAMP markers. Pol Bot J 60:293-299 Sayed, H.A. (2013) Characterization and evaluation of some local and imported olive germplasm. Ph. D. Thesis, Fac. Agric., Cairo Univ., Egypt. 
Shahlaei A, Sepideh Torabi2, fragment length polymorphism (AFLP) methods. MahmoodKhosroshahli, 2014.Efficacy of SCoT and African Journal of Biotechnology 10: 10352-10365.

ISSR markers in the assessment of tomato (Lycopersicumesculentum Mill.) genetic diversity. International Journal of Biosciences | IJB |Vol. 5, No. 2, p. $14-22$

Shannon, C. E. (1949). Communication theory of secrecy systems. Bell System Technical Journal, 28: 656-715

Sheidaia M, Zahra N, Alireza D, Farshid P, Hoda HP, Mehdi H M. Intra-specific morphological and molecular diversity in brown olive (Oleacuspidata) of Iran. Sci Asia. 2010;36:187-193

Sokal, R., and C. Michener (1958).A statistical method for evaluating systematic relationships. Univ. of Kansas Science Bulletin, 38: 1409-1438

Sorkheh K and Khaleghi E (2016) Molecular characterization of genetic variability and structure of olive (Oleaeuropaea L.) germplasm collection analyzed by agro-morphological traits and microsatellite markers. Turk J Agric For 40:583-596

\section{Xiong F, Zhong R, Han Z, Jiang J, He L, Zhuang W, Tang R (2011) Start codon targeted polymorphism for evaluation of functional genetic variation and relationships in cultivated peanut (Arachis hypogaea L.) varieties. MolBiol Rep 38(5):3487-349}

Yeh, F. C., R. C. Yang, T. B. J. Boyle, Z. H. Ye, and J., X. Mao (1997). POPGENE, the user-friendly shareware for population genetic analysis. In. University of Alberta, Canada: Molecular Biology and Biotechnology Centre

Zaher H, Boulouha B, Baaziz M, Sikaoui L, Gaboun F, Sripada M (2011). Morphological and genetic diversity in olive (Oleaeuropaea subsp. europaea L.) clones and varieties. Plant Omics Journal 4: 370-376

Zhan MM, Cheng ZZ, Su GC, et al. Genetic relationships analysis of olive cultivars grown in China. Genet Mol Res. 2015;14(2):5958-5969

Zhang J, Xie W, Wang Y, Zhao X. Potential of Start Codon Targeted (SCoT) markers to estimate genetic Soumaya R. C., Baraket G., Dakhlaoui-Dkhil S., Zehdi- Azouzi S. \&Trifi M. 2011. Molecular research on the genetic diversity of Tunisian date palm (Phoenix dactylifera L.) using the random amplified microsatellite polymorphism (RAMPO) and amplified diversity and relationships among Chinese Elymussibiricusaccessions. Molecules. 2015; 20 (4):5987-6001.

https://doi.org/10.3390/molecules20045987 PMID: 25853316 